\title{
Quality of life and illness perception in working and sick-listed chronic RSI patients
}

\author{
Judith K. Sluiter • Monique H. W. Frings-Dresen
}

Received: 27 September 2006 / Accepted: 22 June 2007 / Published online: 19 July 2007

(C) Springer-Verlag 2007

\begin{abstract}
Objective To study differences between working and sick-listed chronic repetitive strain injury (RSI) patients in the Netherlands with respect to indices of quality of life and illness perception.

Methods In a cross-sectional design, one questionnaire was sent to all 3,250 members of the national RSI patient association. For descriptive purposes, demographics, work status and complaint-related variables such as severity, type, duration, and extent of complaints were asked for. Indices of quality of life were assessed through seven SF36 subscales (physical (role) functioning, emotional role functioning, social functioning, pain, mental health and vitality). A work-ability estimate and VAS scales were used to assess complaint-related decrease in quality of life. Illness perception was assessed through the brief illness perception questionnaire (IPQ-B). Working patients and sicklisted patients were identified. Tests between the two independent groups were performed and $P$-values $<0.01$ were considered significant.

Results Data from 1,121 questionnaires were used. Twothirds of the respondents worked and one-third were sicklisted. Average duration of complaints was over 5 years in both groups. The sick-listed patients reported significantly more severe and extensive complaints than did the working patients. In addition, sick-listed patients reported significantly poorer mental health, physical (role) functioning, emotional role functioning, pain, vitality, and work-ability. With respect to illness perception, both groups showed the
\end{abstract}

J. K. Sluiter $(\square) \cdot$ M. H. W. Frings-Dresen Coronel Institute of Occupational Health,

Academic Medical Center, Universiteit van Amsterdam, Meibergdreef 9, 1105 AZ Amsterdam, The Netherlands

e-mail: j.sluiter@amc.uva.nl same concerns about their complaints, but sick-listed patients had significantly more distorted perceptions in their emotional response, identity, treatment control, personal control, timeline, and life consequences. Complaintrelated decrease in quality of life was $31 \%$ in the working patients and $49 \%$ in the sick-listed patients.

Conclusion The study found a greater number and severe complaints among sick-listed chronic RSI patients and a considerably decreased quality of life because of their complaints. These findings may allow for a better treatment focus in the future.

Keywords Work-related upper extremity musculoskeletal disorders - Repetitive strain injuries · Quality of life $\cdot$ Illness perception

\section{Introduction}

The growing global concerns in the 1990s about the effects of work-related upper extremity musculoskeletal disorders (i.e. Repetitive Strain Injuries, or RSI) on the health and well-being of workers, and about the economic and social impact of these conditions, has led to a variety of research on the international level (e.g. Sluiter et al. 2001; Lee et al. 2005; Bongers et al. 2006; Waters et al. 2007), and in the Netherlands governmental actions, new rules, regulations, and professional guidelines were developed (Sluiter et al. 2001; Douwes et al. 2001; NVAB 2003; Blatter et al. 2004). In addition, the epidemiological studies begun in the 1990s that tried to unravel the multifactorial predisposing and precipitating factors of RSI complaints managed to find several significant factors, albeit the perceived relationships were neither very pronounced nor very specific (e.g. Bongers et al. 2006). 
In contrast to the recently expressed concerns about multidisciplinary curative actions in the US (Feuerstein and Harrington 2006), many preventive ergonomic actions have been introduced in high risk sectors in the Netherlands during the "Covenant" periods. To prevent long-term work disability, occupational physicians have learned to start taking action as early as three weeks after onset of sickness absence for RSI-like complaints. Long-term sickness absence because of RSI-complaints has decreased in the past few years (Bongers et al. 2006). Moreover, when workers' sickness absence is of very long duration, some employers invest in their workers' health by paying for intensive multidisciplinary treatments aimed at a return to work (Meijer et al. 2006).

Despite all these changes, the number of members in, for example, the Dutch RSI Patients' Association doubled during the last seven years, and prevalences of over $25 \%$ for upper extremity complaints are still found; rates are comparable to other European countries (Bongers et al. 2006). All medical professionals deal with patient groups that have medical disorders that may be cared for but not cured with additional costs (Meerding et al. 1998), and also therefore, increasing interest in the patient's perspectives has grown in the last decade. Perspectives about what are important points of interest to deal with in treatment and knowledge about their quality of life both reveal interesting information for specific focus in treatment (Gafni et al. 1998). Illness perception may be distorted more in work-related disorders compared to other diseases when the ability to return and to keep on working in the job that may have caused the health complaints is questioned. Up to now, only little or even no information was available on chronic RSI patients' quality of life and illness representation (Picavet and Hoeymans, 2004; Broadbent et al. 2006). Therefore, in 2005 a study that aimed to describe the working vs. sicklisted RSI patients' perspectives in the Netherlands with respect to their complaints, quality of life, and illness perception was begun in a large group of chronic RSI patients.

\section{Methods}

Population

Patients with RSI were identified by approaching all 3,250 members of the Dutch RSI patients' association. The Dutch RSI patient association was started 11 years ago. In the Netherlands, patients with the same disease are allowed and administratively helped by Governmental Services to join and start an association. Their goal is to gather and spread relevant information to all patients with the same disease in The Netherlands. In addition, their input in sickness-related policy matters is increasingly asked for. Members that were registered in March 2005 were eligible for inclusion. This group defined the study population in this cross-sectional study.

\section{Data collection}

In April 2005 questionnaires were sent by the secretariat of the RSI patients' association to the home addresses of all their current members. An accompanying letter was included from the patients' association. Patients were requested to complete a set of self-report measures. Return envelopes that were addressed directly to the research institute were included as well. One week later, a reminder letter was sent to all members. Data collection was stopped four weeks after sending the reminder. A total of 1,185 $(36 \%)$ questionnaires were returned by mail.

\section{Outcome measurements}

Quality of life was assessed in three ways: Through seven subscales of the Dutch version of the 36-item Short Form Health Survey (Ware and Sherbourne 1992; Aronson et al. 1998): physical role functioning, emotional role functioning, social functioning, pain, mental health, vitality, and physical functioning. Scores ranged between 0 and 100 (higher scores indicated better functioning). Visual analogue scales (VAS) (Streiner and Norman 2003) were used to rate the level of present general quality of life with respect to health $(0=$ the worst imaginable; $10=$ the best imaginable) and to rate the level, retrospectively, of the estimated general quality of life with respect to health before the RSI complaints started $(0=$ the worst imaginable; $10=$ the best imaginable). The patients were also asked to report on their current work-ability by means of an 11-point scale (ranging from 0 for the least ability imaginable to the participant's own maximum level of 10, the highest level imaginable) (e.g. Croon et al. 2005).

The brief illness perception questionnaire (IPQ-B) (Broadbent et al. 2006) assessed cognitive illness perception through items on illness "consequences"(how much does your illness affect your life?), "identity" (how much do you experience symptoms from your illness?), "timeline" (how long do you think your illness will continue?), "personal control" (how much control do you feel you have over your illness?), "treatment control" (how much do you think your treatment can help your illness?). It assessed emotional illness perception with items on illness "concern" (how concerned are you about your illness?) and "emotions" (how much does your illness affect you emotionally? [e.g. does it make you angry, scared, upset, or depressed?]), and it assessed illness understanding with an item on illness "comprehensibility" (how well do you feel 
you understand your illness?). Scores ranged from 0 to 10 , and averages on the group level were calculated (Broadbent et al. 2006). The last question of the IPQ-B is open ended, centring on the most important factors believed to cause the illness.

The demographic, complaint-related, and work activities characteristics were used to describe the two groups. Demographics included gender, age, education, and current work activities. Complaint-related variables were pain and stiffness/tingling intensity (assessed with VAS scales ranging from $0=$ no complaints at all to $10=$ the worst complaints imaginable) (Streiner and Norman 2003), pain duration (in years), extent of pain complaints (number of upper body regions affected) (Sluiter et al. 2001), ranging between 0 and 16 . Work activity characteristics were assessed by four psychosocial work characteristics subscales: work pressure, social support from colleagues or supervisor, and job control (from the "Dutch Questionnaire on the Experience and Assessment of Work", VBBA) (Van Veldhoven and Meijman 1994; Sluiter et al. 2003). VBBA subscale scores ranged between 0 and 100, with higher scores being more unfavourable.

In order to compare the two groups of RSI patients, we classified the "working" group as those patients that had been present at their work for a minimum of $8 \mathrm{~h}$ during the previous week, and the "sick-listed" group were RSI patients with a sickness absence certificate following the Dutch social system (i.e. longer than 1 year sick-listed, or those that stated that they did not work according to their contract hours during the previous week before they filled in the questionnaire).
Statistical analysis

Scale scores were calculated according to the original descriptions of the scales used. VAS scores were calculated in $\mathrm{mm}$, ranging from 0 to 100 . Means and standard deviations were calculated for every outcome. We divided the respondents in two groups, one group of patients that indicated they worked in a paid job, and one group of patients that indicated they were sick-listed. After testing assumptions, either multivariate ANOVA controlling for age, gender, and education level or nonparametric tests (MannWhitney) were performed to test differences between the two groups of RSI patients; $P$-values $<0.01$ were considered significant. Average differences over 1 on a 10 -point scale and over 10 on a 100-point scale were considered clinically important in terms of effect size (Streiner and Norman 2003).

\section{Results}

A total of 1,185 respondents responded, and data from 1,121 questionnaires could be used in the analyses for this study. Table 1 provides a description of demographic and both complaint-related and work-related variables for the groups under study.

RSI patients in the sick-listed group were two years older on average, and this group contained a relatively higher proportion of women and lower proportion of highly educated persons. In the sick-listed group, $76 \%$ was sicklisted longer than one year.

Table 1 Total study population and working vs. sick-listed groups: gender, education, age, pain intensity, pain duration, work status, and workability

\begin{tabular}{|c|c|c|c|c|}
\hline & $\begin{array}{l}\text { Total group } \\
(n=1,121)\end{array}$ & $\begin{array}{l}\text { Working group } \\
(n=745)\end{array}$ & $\begin{array}{l}\text { Sick-listed } \\
\text { group }(n=376)\end{array}$ & $\begin{array}{l}\text { Difference between } \\
\text { groups: } P \text {-value }\end{array}$ \\
\hline Gender ( $\%$ females) & 67 & 62 & 78 & ${ }^{\mathrm{a}}<0.001$ \\
\hline Education (\% high ) & 67 & 71 & 60 & ${ }^{\mathrm{a}}<0.001$ \\
\hline Age in years (mean $(\mathrm{SD}))$ & 40.8 (8.7) & $40.0(8.3)$ & $42.3(9.4)$ & ${ }^{\mathrm{a}}<0.001$ \\
\hline Pain intensity (0-100) (mean (SD)) & $41.3(25.4)$ & $36.2(24.7)$ & $51.6(23.9)$ & ${ }^{\mathrm{a}}<0.001$ \\
\hline $\begin{array}{l}\text { Stiffness/tingling intensity }(0-100) \\
\quad(\text { mean }(\mathrm{SD}))\end{array}$ & $37.8(26.8)$ & $33.7(25.8)$ & $45.7(27.0)$ & ${ }^{\mathrm{a}}<0.001$ \\
\hline Pain duration in years (mean (SD)) & $5.8(3.2)$ & $5.6(3.1)$ & $6.2(3.3)$ & 0.01 \\
\hline $\begin{array}{l}\text { Pain extent } \\
\text { (mean (SD) number of body regions) }\end{array}$ & $6.4(3.9)$ & $5.7(3.6)$ & $7.7(4.1)$ & ${ }^{\mathrm{a}}<0.001$ \\
\hline Work pressure $(0-100)(\text { mean }(\mathrm{sd}))^{\mathrm{b}}$ & $48.4(21.1)$ & $48.7(20.8)$ & $45.9(23.6)$ & 0.885 \\
\hline $\begin{array}{l}\text { Social support from colleagues }(0-100) \\
(\text { mean }(\mathrm{SD}))^{\mathrm{b}}\end{array}$ & $27.8(20.1)$ & $27.4(20.0)$ & $31.5(20.4)$ & 0.157 \\
\hline $\begin{array}{l}\text { Social support from direct supervisor } \\
(0-100)(\text { mean }(\mathrm{SD}))^{\mathrm{b}}\end{array}$ & $35.1(26.2)$ & $34.4(26.1)$ & $42.0(26.1)$ & 0.138 \\
\hline
\end{tabular}

\footnotetext{
${ }^{a}$ Kolmogorov-Smirnov test $P$-values $<0.01$

${ }^{\mathrm{b}}$ Filled in by $n=84$ in the sick-listed group
} 
In both groups, complaints were present for several years and extended over several upper body regions. In both groups, over $85 \%$ received a diagnostic label, provided by a medical professional, that belong to the umbrella term RSI. With respect to complaint-related variables, the patients in the sick-listed group reported significantly more pain in more regions, and they reported more stiffness/tingling complaints. The sick-listed group reported significantly lower ability to work, and no differences between groups were found in the psychosocial work characteristics experienced. With respect to co-morbidity, no other diseases were reported by $46 \%$ in the sick-listed group compared to $64 \%$ in the working group; depression and burnout were reported by 12 and $11 \%$ in the sick-listed group versus 6 and 5\% in the working group. In the working patient group, $35 \%$ filled some kind of administrative function, $11 \%$ worked in IT, $10 \%$ worked in a physical job, and $10 \%$ in a management function. In both groups, almost $80 \%$ reported long- or short-term overexertion during work as the only main cause of the onset of their illness.

Experienced quality of life on the studied SF-36 subscales is shown in Tables 2 and 3. In Table 2, a matrix of zero-order correlation coefficients is shown for the complete population between work-ability, pain intensity, pain

Table 2 Matrix of zero-order correlation coefficients between 1: work-ability, 2: pain intensity, 3: pain duration, 4-10: SF-36 subscales, and 11-18: the B-IPQ outcomes ( $n$ varies between 1,027 and 1,114)

\begin{tabular}{|c|c|c|c|c|c|c|c|c|c|c|c|c|c|c|c|c|c|c|}
\hline & 1 & 2 & 3 & 4 & 5 & 6 & 7 & 8 & 9 & 10 & 11 & 12 & 13 & 14 & 15 & 16 & 17 & 18 \\
\hline 1 work-ability & - & & & & & & & & & & & & & & & & & \\
\hline 2 pain intensiy & -0.48 & - & & & & & & & & & & & & & & & & \\
\hline 3 pain duration & -0.08 & 0.12 & - & & & & & & & & & & & & & & & \\
\hline 4 sf physical role & 0.54 & -0.45 & -0.02 & - & & & & & & & & & & & & & & \\
\hline 5 sf mental health & 0.34 & -0.25 & 0.03 & 0.32 & - & & & & & & & & & & & & & \\
\hline 6 sf emotional role & 0.26 & -0.18 & 0.05 & 0.31 & & - & & & & & & & & & & & & \\
\hline $\begin{array}{l}7 \text { sf social } \\
\quad \text { functioning }\end{array}$ & -0.01 & 0.05 & -0.01 & -0.07 & -0.01 & 0.09 & - & & & & & & & & & & & \\
\hline 8 sf pain & 0.61 & -0.72 & -0.05 & 0.59 & 0.31 & 0.24 & -0.03 & - & & & & & & & & & & \\
\hline 9 sf vitality & 0.40 & -0.30 & 0.01 & 0.40 & 0.75 & 0.47 & -0.08 & 0.39 & - & & & & & & & & & \\
\hline $\begin{array}{l}10 \text { sf physical } \\
\text { functioning }\end{array}$ & 0.60 & -0.52 & -0.18 & 0.48 & 0.27 & 0.22 & -0.02 & 0.61 & 0.38 & - & & & & & & & & \\
\hline 11 consequences & -0.61 & 0.51 & 0.08 & -0.58 & -0.35 & -0.27 & -0.001 & -0.62 & -0.41 & -0.49 & - & & & & & & & \\
\hline 12 timeline & -0.13 & 0.18 & 0.32 & -0.10 & -0.03 & 0.01 & 0.01 & -0.15 & -0.07 & -0.16 & 0.19 & - & & & & & & \\
\hline 13 personal control & 0.44 & -0.36 & -0.004 & 0.35 & 0.33 & 0.18 & -0.001 & 0.42 & 0.35 & 0.34 & -0.36 & -0.06 & - & & & & & \\
\hline 14 treatment control & 0.29 & -0.19 & -0.09 & 0.16 & 0.10 & 0.05 & 0.04 & 0.21 & 0.15 & 0.15 & -0.16 & -0.16 & 0.33 & - & & & & \\
\hline 15 identity & -0.51 & 0.64 & 0.07 & -0.54 & -0.29 & -0.23 & 0.04 & -0.67 & -0.35 & -0.49 & 0.68 & 0.23 & -0.33 & -0.10 & - & & & \\
\hline 16 concern & -0.38 & 0.46 & -0.03 & -0.46 & -0.35 & -0.27 & 0.01 & -0.49 & -0.37 & -0.30 & 0.57 & 0.16 & -0.36 & -0.10 & 0.58 & - & & \\
\hline 17 comprehensibility & 0.20 & -0.16 & 0.04 & 0.22 & 0.20 & 0.14 & -0.03 & 0.19 & 0.21 & 0.12 & -0.21 & 0.00 & 0.31 & 0.22 & -0.16 & -0.29 & - & \\
\hline $\begin{array}{l}18 \text { emotional } \\
\text { response }\end{array}$ & -0.38 & 0.35 & -0.07 & -0.46 & -0.51 & -0.39 & 0.01 & -0.41 & -0.47 & -0.25 & 0.59 & 0.08 & -0.35 & -0.08 & 0.48 & 0.64 & -0.27 & - \\
\hline
\end{tabular}

Table 3 Mean (SD) scores by groups on SF-36 subscales physical role functioning, mental health, emotional role functioning, social functioning, pain, vitality, physical functioning, and work-ability

\begin{tabular}{|c|c|c|c|c|}
\hline & $\begin{array}{l}\text { Total group } \\
(n=1,121)\end{array}$ & $\begin{array}{l}\text { Working } \\
\text { group }(n=745)\end{array}$ & $\begin{array}{l}\text { Sick-listed } \\
\text { group }(n=376)\end{array}$ & $\begin{array}{l}\text { Difference between } \\
\text { groups: } P \text {-value }\end{array}$ \\
\hline \multicolumn{5}{|l|}{ SF-36 scales $(0-100)$ (mean (SD)) } \\
\hline Physical role functioning & $34.7(38.2)$ & $43.4(39.2)$ & $17.0(29.0)$ & ${ }^{\mathrm{a}}<0.001$ \\
\hline Mental health & $68.5(16.7)$ & $70.6(15.6)$ & $64.3(18.0)$ & ${ }^{\mathrm{a}}<0.001$ \\
\hline Emotional role functioning & $73.9(38.3)$ & $78.7(34.8)$ & $64.1(43.1)$ & ${ }^{\mathrm{a}}<0.001$ \\
\hline Social functioning & $54.5(9.4)$ & $54.6(8.9)$ & $54.2(10.4)$ & 0.208 \\
\hline Pain & $54.7(21.6)$ & $60.7(19.2)$ & $42.7(22.0)$ & a $<0.001$ \\
\hline Vitality & $53.6(17.9)$ & $55.7(17.1)$ & $49.3(18.6)$ & ${ }^{\mathrm{a}}<0.001$ \\
\hline Physical functioning & $76.5(18.0)$ & $81.7(14.6)$ & $65.9(19.6)$ & ${ }^{\mathrm{a}}<0.001$ \\
\hline Work-ability $(0-10)$ (mean (SD)) & $5.4(2.7)$ & $6.6(1.8)$ & $3.1(2.6)$ & ${ }^{\mathrm{a}}<0.001$ \\
\hline
\end{tabular}

${ }^{a}$ Kolmogornov-Smirnov test $P$-values $<0.01$ 
duration, the SF-36 subscales, and the eight B-IPQ dimensions. The highest correlation coefficients were found between the two SF-36 subscales mental health and vitality $(r=0.75)$, and the SF-36 subscale pain and VAS scale pain intensity $(r=0.72)$.

As shown in Table 3, the average scores of all scales but social functioning differed significantly between the two groups to the detriment of the sick-listed RSI patients on the other SF-36 subscales. Clinically relevant differences were found in work-ability and in the SF-36 scales for physical role functioning, emotional role functioning, pain, and physical functioning.

General quality of life with respect to present health was rated as 52.7 on average (SD: 24.4) in the total group of RSI patients, and the average in the working group and sick-listed groups were 57.9 and 42.2 , respectively. The group difference was significant $(P$-value KolmogornovSmirnov test $<0.001)$. In contrast, the estimated general quality of life with respect to health before the onset of RSI complaints was rated as 83.1 on average (SD: 15.4 ) in the total group of RSI patients. There was only a non-significant difference in the average scores between groups (83.1 in the working group and 83 in the sick-listed group $(P$ value Kolmogornov-Smirnov test $=0.796)$ ). Combining these results, the general quality of life with respect to health was subjectively decreased by $37 \%$ in the total group over time. However, the difference in decrease was significant $($ Kolmogornov-Smirnov test, $P$-value $<0.001$ ): only $31 \%$ in the working group but $49 \%$ in the sick-listed group of patients.

Scores on the eight illness perception dimensions are shown in Table 4.

With the exception of the dimension timeline and comprehensibility, there was a significant difference in the six other illness perception dimensions between the two groups. Clinically relevant differences between the two groups to the detriment of the sick-listed RSI patients were found for the illness perception dimensions of "consequences", "personal-" and "treatment-control", and "identity".

\section{Discussion}

The aim of the present study was to describe working vs. sick-listed RSI patients' perspectives in the Netherlands in 2005 with respect to their complaints, quality of life, and illness perception. The sick-listed RSI patients reported more severe and extensive complaints in the upper extremity, but the long duration ( 6 years) of their complaints was comparable to the working RSI patients. The sick-listed patients, however, experienced a considerably more decreased quality of life because of their complaints, as well as more distorted illness perceptions.

The quality of life in sick-listed patients was lower than that of the working patients when the SF-36 subscales scores were taken into account. Interestingly, both groups showed comparable but low social functioning scores (averaging around 55). This was also actually quite low compared to a group of patients with rheumatoid arthritis, who averaged over 70 and compared with a small sample of Dutch workers with RSI who averaged 79 (Sprangers et al. 2000; Picavet and Hoeymans 2004). The experienced quality of life decrease over time was found to be substantial in both groups, which might be explained by the severity, duration, and extent of the reported complaints. It is possible to argue that the anchor question that was used to calculate the quality of life decrease was posed post-hoc. But that was one of the proposed solutions among quality of life researchers in the debate about changed perspectives and response shift: by asking for the two rates at a given time in the form of an existing test, there cannot be any recalibration, re-evaluation of re-prioritization, and re-conceptualization (Osborne et al. 2006; Visser et al. 2005).

This may have been the first time that illness representation was assessed in a large group of RSI patients using the recently described brief illness perception questionnaire (IPQ-B) (Broadbent et al. 2006). Illness representation covers the dimensions of illness identity, consequences, cause, timeline, and cure or control. These perceptions about the illness influence patient behaviours, and changing perceptions may improve recovery (e.g. Petrie et al. 2002). If an
Table 4 Mean (SD) illness perception scores (B-IPQ) by groups

${ }^{\text {a }}$ Kolmogornov-Smirnov test $P$-values $<0.01$

\begin{tabular}{llllc}
\hline $\begin{array}{l}\text { Illness perception } \\
\text { dimensions }\end{array}$ & $\begin{array}{l}\text { Total group } \\
(n=1,121)\end{array}$ & $\begin{array}{l}\text { Working group } \\
(n=745)\end{array}$ & $\begin{array}{l}\text { Sick-listed } \\
\text { group }(n=376)\end{array}$ & $\begin{array}{l}\text { Difference between } \\
\text { groups: } P \text {-value }\end{array}$ \\
\hline Consequences & $6.3(2.6)$ & $5.6(2.5)$ & $7.6(2.1)$ & ${ }^{\mathrm{a}}<0.001$ \\
Timeline & $8.3(2.0)$ & $8.2(2.1)$ & $8.5(1.7)$ & 0.557 \\
Personal control & $6.3(2.0)$ & $6.7(1.8)$ & $5.6(2.1)$ & ${ }^{\mathrm{a}}<0.001$ \\
Treatment control & $5.2(2.6)$ & $5.7(2.5)$ & $4.4(2.6)$ & ${ }^{\mathrm{a}}<0.001$ \\
Identity & $6.2(2.4)$ & $5.8(2.4)$ & $7.1(2.1)$ & ${ }^{\mathrm{a}}<0.001$ \\
Concern & $5.5(2.6)$ & $5.2(2.6)$ & $6.1(2.6)$ & ${ }^{\mathrm{a}}<0.001$ \\
Comprehensibility & $6.9(2.1)$ & $7.1(2.0)$ & $6.6(2.3)$ & 0.014 \\
Emotional response & $5.4(2.6)$ & $5.1(2.6)$ & $6.0(2.5)$ & ${ }^{\mathrm{a}}<0.001$ \\
\hline
\end{tabular}


average difference of over 1 on a $0-10$ point scale is considered clinically relevant, illness consequences, personal control, treatment control, and identity (i.e. the number of symptoms because of the illness) clearly differed between sick-listed and working RSI patients. We believe that it would be useful to focus future informational treatment strategies in the sick-listed patient group on changing their illness perception.

We successfully compared two fairly large groups of chronic RSI patients with respect to their current complaints, quality of life, and illness perception. However, some methodological considerations are in place: (1) the used case-definition to identify sick-listed RSI patients may have influenced the outcomes although it is not clear in what direction this may have caused a bias; (2) because not all variables complied with all assumptions for multivariate testing, that would have allowed for controlling for different possible confounders, non-parametric test outcomes have been presented. Post-hoc multivariate testing did not show any differences in the outcomes as were presented. (3) It is acknowledged that a relatively modest proportion of the total study population responded. Considering the variation in responses and the main purpose of this study, the response should not be considered as a bias. Our population, however, is a selected population in several ways and this has been described in the methods section: participants were members of the RSI patients association, they had long-term complaints, it was not possible to take a random sample in the theoretically existing Dutch group of chronic RSI patients who work or are sick-listed, and the number of responders of the total sample was not as much as would be desirable. However, the diagnostic label that was communicated with over $85 \%$ of these chronic patients by different physicians was one of the syndromes that fall under the umbrella diagnosing label of "RSI" (Sluiter et al. 2001). In addition, comparisons between two groups of this specific group of patients were reported upon for this study. Summarizing, besides its possible shortcomings, this study is thought to be unique with respect to studying a large group of chronic RSI patients as most of the published literature on work-related upper extremity musculoskeletal disorders deal with acute and sub-acute populations.

It would be interesting to study how the relation between the variables under study developed over time: if the severity of complaints, quality of life level, and illness perception dimensions are relatively stable over time in this subgroup of chronic patients, they could be used as prognostic factors to decide on interventions with respect to future ability to work. It may also be that if activities are increased because of work resumption, they will act as "intervention" in the place-then-train ratio and influence the measures over time. We do know that the differences in the severity of RSI complaints and quality of life indices, to the detriment of the sick-listed group of RSI patients, could be used as an indication for referral to multidisciplinary treatment programmes, because all of these parameters have recently been shown to be influenced positively, even in patients with long-term complaints (Meijer et al. 2006).

Acknowledgments This study was performed in cooperation with the Dutch RSI patients' association. We would like to thank their scientific board and all the patients who were willing to share their experiences.

\section{References}

Aaronson NK, Muller M, Cohen PD, Essink-Bot ML, Fekkes M, Sanderman $R$ et al (1998) Translation, validation, and norming of the Dutch language version of the SF-36 Health Survey in community and chronic disease populations. J Clin Epidemiol 51(11):1055-1068

Blatter BM, Bongers PM, Dieën JH van, Kempen PM van, Kraker H de, Miedema H, Reijneveld CN, Vet HCW de (2004) RSI measures: prevention, treatment and return to work. [RSI-maatregelen: preventie, behandeling en reïntegratie]. Dutch Ministry of Social Affairs and Work, The Hague

Bongers PM, IJmker S, Heuvel S van den, Blatter BM (2006) Epidemiology of work related neck and upper limb problems: psychosocial and personal risk factors (part I) and effective interventions from a bio behavioural perspective (part II). J Occup Rehabil 16(3):279-302. doi:10.1007/s10926-006-9044-1

Broadbent E, Petrie KJ, Main J, Weinman J (2006) The Brief Illness Perception Questionnaire. J Psychosom Res 60:631-637

Croon EM de, Sluiter JK, Nijssen TF, Kammeijer M, Dijkmans BAC, Lankhorst GJ, Frings-Dresen MHW (2005) Work ability of Dutch employees with rheumatoid arthritis. Scand J Rheumatol 34(4):277-283. doi:10.1080/03009740510018615; (AN 17961089)

Douwes M, Blatter BM, Thé KH, Miedema MC (2001) Measures during VDU work against RSI [Maatregelen RSI bij beeldschermwerk]. The Ministry of Social Affairs and Work, The Hague

Feuerstein M, Harrington CB (2006) Secondary prevention of workrelated upper extremity disorders: recommendations from the Annapolis conference. J Occup Rehabil 16(3):401-409. doi:10.1007/s10926-006-9030-7

Gafni A, Charles C, Whelan T (1998) The physician-patient encounter: the physician as a perfect agent for the patient versus the informed treatment decision-making model. Soc Sci Med 47:347-354

Lee HY, Yeh WY, Chen CW, Wang JD (2005) Prevalence and psychosocial risk factors of upper extremity musculoskeletal pain in industries of Taiwan: a nationwide study. J Occup Health 47:311-318

Meerding WJ, Bonneux L, Polder JJ, Koopmanschap MA, Van der Maas PJ (1998) Demographic and epidemiological determinants of healthcare costs in Netherlands: cost of illness study. Br Med J 317:111-115

Meijer EM, Sluiter JK, Heyma A, Sadiraj K, Frings-Dresen MHW (2006) Cost-effectiveness of multidisciplinary treatment in sicklisted patients with upper extremity musculoskeletal disorders: a randomized, controlled trial with one-year follow-up. Int Arch Occup Environ Health 79: 654-664

NVAB (2003) Practice guideline occupational physicians complaints of arm, shoulder or neck. [Handelen van de bedrijfsarts bij werknemers met Klachten aan arm, schouder of nek.] ISBN 9076721068

Osborne RH, Hawkins M, Sprangers MAG (2006) Change of perspective: a measurable and desired outcome of chronic disease self-management intervention programs that violates the premise of preintervention/postintervention assessment. Arthritis Rheum 55(3):458-465 
Petrie KJ, Cameron LD, Ellis CJ, Buick D, Weinman J (2002) Changing illness perceptions after myocard infarction: an early intervention randomized controlled trial. Psychosom Med 64:580-586

Picavet HSJ, Hoeymans N (2004) Health related quality of life in multiple musculoskeletal diseases: SF-36 and EQ-5D in the DMC3 study. Ann Rheum Dis 63:723-729

Sluiter JK, Rest KM, Frings-Dresen MHW (2001) Criteria document for evaluation of the work-relatedness of upper extremity musculoskeletal disorders. Scand J Work Environ Health 27(suppl 1):1-102

Sluiter JK, Croon EM de, Meijman TF, Frings-Dresen MHW (2003) Need for recovery from work-related fatigue and its role in the development and prediction of subjective health complaints. Occup Environ Med 60(suppl 1):i62-i70

Sprangers MA, de Regt EB, Andries F, van Agt HM, Bijl RV, de Boer JB, Foets M, Hoeymans N, Jacobs AE, Kempen GI, Miedema HS, Tijhuis MA, de Haes HC (2000) Which chronic conditions are associated with better or poorer quality of life? J Clin Epidemiol 53(9):895-907
Streiner DL, Norman GR (2003) Health measurement scales, 3rd edn. Oxford University Press, Oxford, p 33-34;209

Van Veldhoven MJPM, Meijman TF (1994) Questionnaire on psychosocial job demands and job stress. [Het meten van psychosociale arbeidsbelasing met een vragenlijst: de Vragenlijst Beleving en Beoordeling van de Arbeid (VBBA)]. NIA, Amsterdam

Visser MRM, Oort FJ, Sprangers MAG (2005) Methods to detect response shift in quality of life data: a convergent validity study. Qual Life Res 14:629-639

Ware JE Jr, Sherbourne CD (1992) The MOS 36-item short-form health survey (SF-36). I. Conceptual framework and item selection. Med Care 30:473-83

Waters TR, Dick RB, Davis-Barkley J, Krieg EF (2007) A cross-sectional study of risk factors for musculoskeletal symptoms in the workplace using data from the general social survey (GSS). J Occup Environ Med 49(2):172-184 